\title{
RANCANG BANGUN CHARger OTOMATIS Pengontrol Daya dan Waktu Berbasis ARDUINO UNO
}

\author{
Mohammad Wahyu Habibulloh') dan Kurnia Paranita Kartika ${ }^{2)}$ \\ 1,2) Universitas Islam Balitar \\ Fakultas Teknologi Informasi \\ e-mail: rhyouwahyu38@gmail.com ${ }^{1)}$ kurnia.paranitha@ gmail.com ${ }^{2)}$
}

\begin{abstract}
Pada tugas akhir ini dibahas mengenai perancangan dan pembuatan charger otomatis pengontrol daya dan waktu berbasis arduino UNO. Pada charger biasa masih belum memiliki mekanisme untuk memutus aliran listrik yang masuk pada charger sepenuhnya, sehingga peneliti memiliki ide untuk mengembangkan charger otomatis untuk meningkatkan efisiensi pengisian baterai serta untuk meningkatkan umur pakai baterai smartphone. Alat ini digunakan untuk melakukan pengontrolan pada pengisian smartphone dengan dasar baterai yang digunakan yaitu kepasitas 4100mAH, dengan charger yang digunakan adalah charger xiaomi 0.35A. dengan menggunakan keypad sebagai pengimput sisa persentase baterai, charger akan mengisi baterai sesuai dengan waktu yang telah disetting pada masing-masing tombol keypad. Lamanya waktu pengisian baterai ditampilkan pada LCD. Ketika waktu pengisian telah selesai relay yang tersambung pada stopkontak charger akan memutus listrik yang mengarah pada charger untuk menghentikan proses pengisian dan buzzer akan menyala sebagai indikator pengisian telah selesai dan LCD akan menampilkan tulisan "pengisian telah selesai".

Melalui pengujian yang dilakukan oleh peneliti sendiri dan pengujian alat kepada user pengisian baterai dengan menggunakan charger otomatis berbasis arduino UNO didapatkan hasil yaitu charger otomatis dapat mengisi baterai dengan keakuratan dapat mencapai 98\% hingga 99\% dari kapasitas baterai dan dapat menghentikan pengisian sesuai waktu yang ditentukan.

Saran yang dapat diberikan oleh penulis untuk penelitian selanjutnya yaitu penggunaan keypad custom yang dilengkapi dengan keterangan pada setiap tombol untuk memudahkan user, penggunaan rtc untuk melakukan penghitungan waktu pengisian baterai, serta pengembangan pada sumber daya cadangan alat jika terjadi pemadaman listrik.
\end{abstract}

Kata Kunci : Charger, Baterai, Smartphone, Arduino

Abstract : This final project discusses the design and manufacture of an arduino UNO-based power and time controller automatic charger. On an ordinary charger still does not have a mechanism to cut off the electricity that goes into the charger completely, so researchers have an idea to develop an automatic charger to increase the efficiency of battery charging and to increase the battery life of smartphones. This tool is used to control the charging of a smartphone on the basis of a battery that is used is a capacity of $4100 \mathrm{mAH}$, with the charger used is the Xiaomi 0.35A charger. the remaining percentage of the battery is controlled by using a keypad, the charger will charge the battery in accordance with the time set on each keypad button. The amount of time the battery is charged is displayed on the LCD. When the charging time has finished the relay that is connected to the charger outlet will disconnect the electricity that leads to the charger to stop the charging process and the buzzer will light up as the charging indicator has finished and the LCD will display the words "charging has finished".

Through testing conducted by the researchers themselves and testing the device to the user charging the battery using an arduino UNO-based automatic charger, the results are that the automatic charger can charge the battery with accuracy reaching $98 \%$ to $99 \%$ of the battery capacity and can stop charging according to the specified time.

Suggestions that can be given by the authors for further research are the use of a custom keypad that is equipped with information on each key to facilitate the user, the use of RTC to calculate battery charging time, as well as the development of a backup power source in the event of a power outage.

Keywords : Charger, Smartphone,Arduino

\section{PENDAhUluan}

$\mathrm{P}$ erkembangan teknologi yang sangat pesat setiap tahunnya selalu memunculkan terobosan-terobosan baru diberbagai bidang. Seperti contohnya dibidang komunikasi. Cara berkomunikasi sudah sangat 
berbeda dengan adanya perkembangan telepon pintar (smartphone) yang banyak memiliki fitur-fitur terbaru yang semakin memudahkan penggunanya. Teknologi terbaru menggunakan teknologi mobile (dapat dibawa kemana-mana), yang mana teknologi yang bersifat mobile tentunya membutuhkan sumber daya untuk mengoperasikan peralatan tersebut. Sumberdaya yang digunakan adalah baterai.

Seperti yang dikutip dari website kementerian Komunikasi dan informatika republik Indonesia "pada tahun 2018 jumlah pengguna smartphone aktif diindonesia mencapai lebih dari 100 juta". Jumlah sebanyak itu tentunya akan menimbulkan permasalahan kelak[1]. Diantaranya yaitu pemborosan listrik maupun ancaman kebakaran karena meledaknya baterai smarphone ataupun konsleting pada charger smarphone.

Dari permasalahan tersebut penulis memiliki gagasan untuk menciptakan sebuah alat yang mampu meningkatkan efisiensi pengisian daya pada baterai sehingga baterai menjadi lebih awet dengan harapan dapat memperpanjang umur penggunaan baterai sekaligus memberikan keamanan bagi pengguna ketika mengisi daya baterai. Alat ini dibuat dengan menggunakan relay sebagai saklar yang akan mengatur pengisian daya pada baterai. alat ini menggunakan keypad sebagai media penginputan persentase sisa baterai. Arduino UNO sebagai mikrokontroler akan disambungkan dengan relay untuk memutus arus listrik ketika waktu pengisian daya sudah habis.

\section{Metode PEnelitian}

Penelitian yang dilakukan menggunakan metode Research and Development (Penelitian pengembangan). Menurut Sugiyono (2016) menjelaskan metode penelitian metode penelitian dan pengembangan termasuk dalam kategori penelitian "need to do" yaitu penelitian yang hasilnya digunakan untuk membantu pelaksanaan pekerjaan sehingga bila pekerjaan tersebut dibantu dengan produk yang dihasilkan maka akan semakin produktif,efektif dan efesien. Metode penelitian dan pengembangan adalah ternasuk dalam metode penelitian kombinasi model sequentiall berurutan[2]

\section{A. Identifikasi Masalah}

Berdasarkan studi literatur dan wawancara didapatkan permasalahan yaitu masih kurangnya alat bantu proses pengisian daya pada baterai smartphone yang dapat meningkatkan efisiensi dan keamanan pada saat mengisi baterai, sehingga dapat menimbulkan dampak pada kerusakan pada baterai, charger, ataupun smartphone.

\section{B. Pengumpulan Data}

Waktu dan tempat penelitian dilakukan di Desa Karangsono, RT 03 RW3, Kecamatan Kanigoro pada tanggal 16 desember 2018 hingga 3 februari 2019 untuk tahap awal penelitian. Penelitian tahap lanjut dilaksanakan mulai bulan maret 2019 dengan target penelitian selesai sebelum bulan agustus 2019 . Penelitian dilakukan dengan :

\section{a. Metode Observasi}

Observasi dilakukan dengan melakukan pengamatan pada proses pengisian daya baterai smartphone dan hal-hal yang berkaitan. Observasi dilakukan pada tanggal 16 Desember 2018 di desa Karangsono RT 02 RW 01. Observasi dilakukan pada smartphone dengan tipe xiaomi redmi note 4x dengan kapasitas baterai 4100mAH.

b. Wawancara

Dilakukan dengan melakukan tanya jawab dengan pengguna smartphone. Wawancara dilakukan pada 18 Januari 2019 bertempat di desa Karangsono RT 03 RW 03.

\section{c. Studi Literatur}

Teknik pengumpulan data dilakukan dengan menggunakan bahan referensi yang sesuai dan relevan dengan penelitian yang akan dilakukan yang diantaranya yaitu menggunakan referensi dari penelitian terdahulu yang sejenis, buku-buku terkait dengan masalah yang dibahas, dan sebagainya. Studi pustaka dilakukan mulai tanggal 18 Desember 2018 hingga 6 Januari 2019. 
ANTIVIRUS: Jurnal Ilmiah Teknik Informatika (p - ISSN: 1978 - 5232; e - ISSN: 2527 - 337X)

Vol. 12 No. 1 Mei 2019, pp. $48-58$

Berdasarkan hasil observasi pada proses pengisian baterai smartphone menggunakan charger xiaomi 0,25A didapatkan hasil berikut :

\begin{tabular}{|c|c|c|c|c|c|}
\hline \multirow[b]{2}{*}{ No } & \multirow[b]{2}{*}{ Persentase } & \multicolumn{4}{|c|}{ pengamatan pertama } \\
\hline & & $\begin{array}{l}\text { data jam } \\
\text { pengisian }\end{array}$ & $\begin{array}{c}\text { selisih } \\
\text { waktu antar } \\
\text { persentase }\end{array}$ & $\begin{array}{l}\text { total waktu } \\
\text { pengisian }\end{array}$ & Daya \\
\hline 1 & $0 \%$ & 08.30 & 0 menit & 2 jam 28 menit & $1750-1900 \mathrm{mAH}$ \\
\hline 2 & $5 \%$ & 08.35 & 5 menit & 2 jam 23 menit & $1710-1900 \mathrm{mAH}$ \\
\hline 3 & $10 \%$ & 08.42 & 7 menit & 2 jam 16 menit & $1800-1850 \mathrm{mAH}$ \\
\hline 4 & $15 \%$ & 08.49 & 7 menit & 2 jam 09 menit & $1800-1850 \mathrm{mAH}$ \\
\hline 5 & $20 \%$ & 08.57 & 8 menit & 2 jam 01 menit & $1800-1850 \mathrm{mAH}$ \\
\hline 6 & $25 \%$ & 09.04 & 7 menit & 1 jam 54 menit & $1800-1850 \mathrm{mAH}$ \\
\hline 7 & $30 \%$ & 09.10 & 6 menit & 1 jam 48 menit & $1800-1850 \mathrm{mAH}$ \\
\hline 8 & $35 \%$ & 09.16 & 6 menit & 1 jam 42 menit & $1800-1850 \mathrm{mAH}$ \\
\hline 9 & $40 \%$ & 09.22 & 6 menit & 1 jam 36 menit & $1800-1850 \mathrm{mAH}$ \\
\hline 10 & $45 \%$ & 09.27 & 5 menit & 1 jam 31 menit & $1760-1850 \mathrm{mAH}$ \\
\hline 11 & $50 \%$ & 09.32 & 5 menit & 1 jam 26 menit & $1640-1790 \mathrm{mAH}$ \\
\hline 12 & $55 \%$ & 09.37 & 5 menit & 1 jam 21 menit & $1660-1710 \mathrm{mAH}$ \\
\hline 13 & $60 \%$ & 09.42 & 5 menit & 1 jam 16 menit & $1630-1640 \mathrm{mAH}$ \\
\hline 14 & $65 \%$ & 09.48 & 6 menit & 1 jam 10 menit & $1370-1560 \mathrm{mAH}$ \\
\hline 15 & $70 \%$ & 09.52 & 6 menit & 1 jam 06 menit & $1350-1360 \mathrm{mAH}$ \\
\hline 16 & $75 \%$ & 09.57 & 5 menit & 1jam 01 menit & 990-1220 mAH \\
\hline 17 & $80 \%$ & 10.00 & 7 menit & 58 menit & $950-970 \mathrm{mAH}$ \\
\hline 18 & $85 \%$ & 10.07 & 7 menit & 51 menit & $750-900 \mathrm{mAH}$ \\
\hline 19 & $90 \%$ & 10.18 & 11 menit & 40 menit & $680-680 \mathrm{mAH}$ \\
\hline 20 & $95 \%$ & 10.33 & 15 menit & 25 menit & $450-460 \mathrm{mAH}$ \\
\hline 21 & $100 \%$ & 10.58 & 25 menit & & \\
\hline
\end{tabular}

Dengan menggunakan hasil observasi diatas akan digunakan sebagai dasar untuk membuat sistem pengisian otomatis.

\section{Desain Produk}

Desain alat dirancang dengan menyesuaikan kebutuhan pengisian baterai pada smartphone sesuai dengan rancangan yang telah dibuat. Desain charger otomatis adalah seperti berikut :

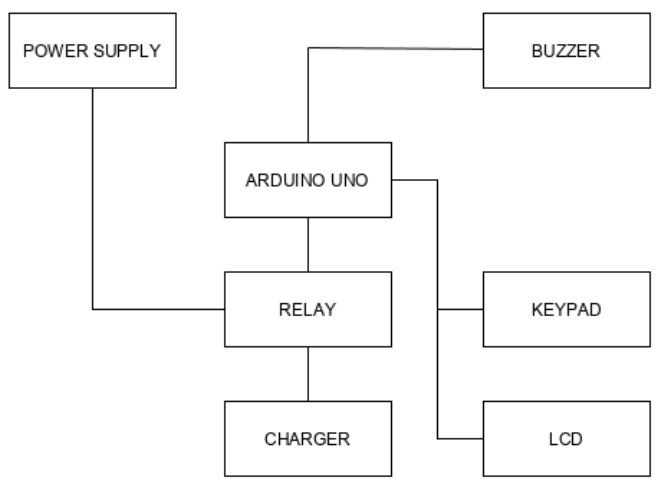

Gambar 1. Desain awal alat 
Alat ini akan dibuat dengan menggunakan casing akrilik bening, Dengan komponen yang digunakan yaitu keypad, relay, LCD, dan buzzer. Semua komponen tersebut akan dikontrol oleh arduino UNO.Diagram blok yang digunakan rangkaian umun dalam peletakan dan perakitan komponen dalam charger otomatis adalah sebagai berikut :

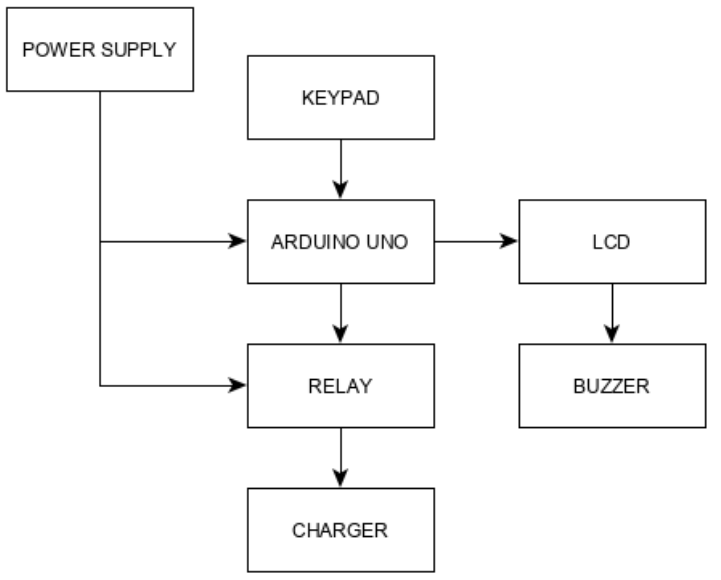

Gambar 2. Diagram Blok

Dari diagram blok diatas dapat dilihan alur dan fungsi dari masing-masing blok . power supply akan menyediakan kebutuhan listrik untuk semua komponen . arduino akan mengontrol semua komponen . keypad berfungsi sebagai input untuk memasukkan sisa persentase baterai yang akan diteruskan kepada arduino dan mengontrol relay . buzzer akan berfungsi sebagai output.

Berdasarkan desain awal dan diagram blok yang telah dibuat diawal peneliti membuat flowchart sebagai panduan untuk membuat program untuk menjalankan alat. Flowchart atau Bagan alir adalah bagan (chart) yang menunjukkan alir (flow) di dalam program atau prosedur sistem secara logika. Bagan alir (flowchart) digunakan terutama untuk alat bantu komunikasi dan untuk dokumentasi.[3]

Flowchart yang digunakan pada ada alat yaitu :

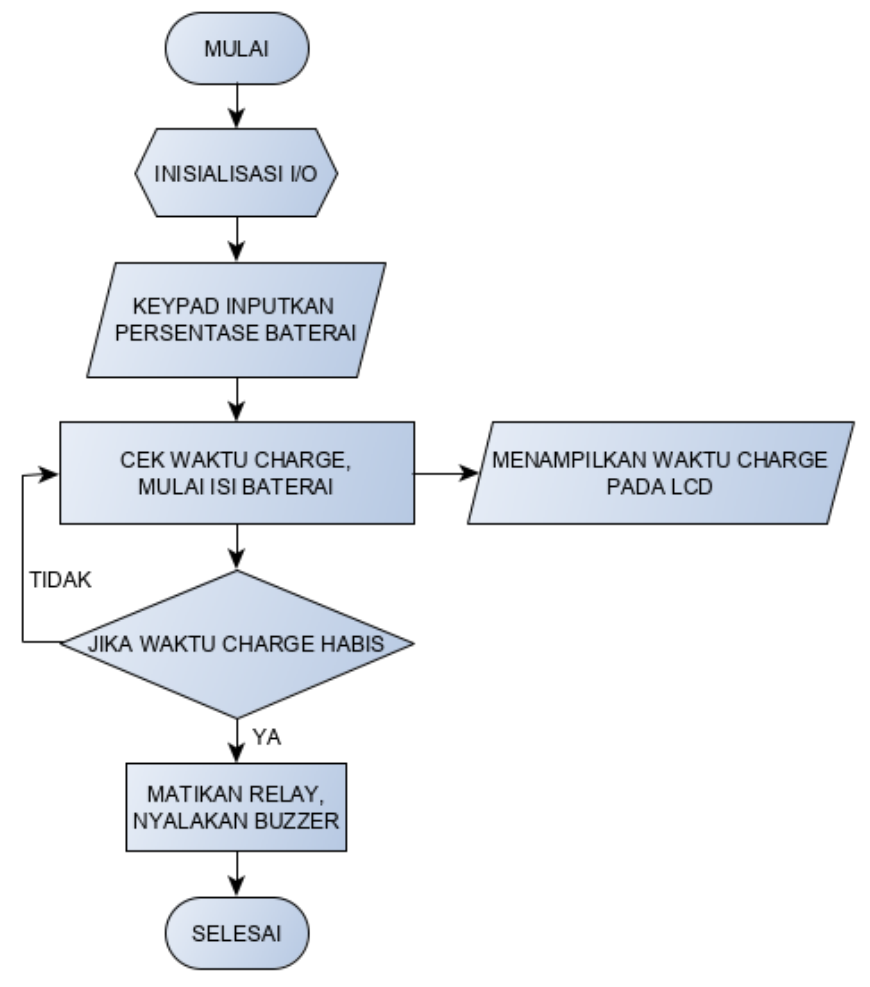

Gambar 3. Flowchart charger 
Keterangan dari flowchart rangkaian charger otomatis pengendali daya dan waktu :

Mulai, merupakan kondisi awal sistem bekerja.Inisialisasi I/O adalah proses pengecekan semua komponen yang bekerja pada alat yaitu diantaranya keypad,relay,LCD,charger,buzzer, apakah seluruh komponen sudah siap digunakan atau tidak. Dan juga untuk menentukan komponen-komponen mana saja yang menjadi input dan mana yang menjadi output.Penginputan persentase sisa baterai dilakukan dengan melalui keypad dengan tombol yang telah disetting sesuai dengan range persentase sisa baterai. Penghitungan waktu pengisian daya baterai dilakukan membaca database sesuai dengan persentase sisa daya baterai dan dilanjutkan dengan mulai mengisi daya baterai.

LCD akan menampilkan waktu yang dibutuhkan untuk pengisian baterai sesuai dengan persentase sisa daya baterai yang diinputkan melalui keypad.Pada kondisi yang telah ditentukan jika waktu pengisian baterai masih belum selesai maka pengisian akan terus dilanjutkan sesuai dengan delay waktu yang telah ditentukan.Apabila waktu pengisian sudah selesai maka relay akan mematikan charger dan buzzer akan berbunyi untuk menandakan bahwa waktu pengisian baterai sudah habis.Selesai, sistem berakhir

\section{Validasi Produk}

Berdasarkan validasi yang telah dilakukan ke ahli dibidangnya, telah dilakukan validasi pada setiap komponen yang bekerja secara keseluruhan menjadi satu alat. Dengan hasil validasi bahwa alat layak digunakan sebagai alat bantu untuk meningkatkan hasil dari proses pengisian baterai. Dengan catatan dari validator yaitu penutupan pada lubang stop kontak yang tidak digunakan dan menambahkan prosedur penggunaan pada alat.

\section{E. Uji Coba Produk}

Uji coba produk dilakukan ketika produk sudah jadi berdasarkan desain yang telah diperbaiki setelah melalui proses validasi. Uji coba ini dilakukan untuk menguji kerja alat secara langsung kepada user dengan hasil uji :

1. User masih belum pernah mengetahui penggunaan alat kontrolo tomatis ini sebelumnya.

2. Menurut pendapat user alat ini dapat membantu untuk mengotrol proses pengisian baterai agar tidak overcharge.

3. Penggunaan alat ini dirasa efektif oleh user.

\section{HASIL DAN PEMBAHASAN}

\section{A. Hasil Penelitian dan Pembahasan}

Pada charger otomatis pengontrol daya dan waktu ini penggunaannya bagi user dirasa efektif karena dengan alat ini user dapat mengontrol waktu pengisian baterai sesuai dengan persentase sisa baterai. Sehingga user dapat merasa aman karena ketika waktu pengisian selesai maka alat akan mati dan tidak terjadi overcharge.

\section{B. Pengujian Kontroler}

Kontroler yang digunakanan pada alat ini adalah Arduino UNO. Arduino UNO adalah papan mikrokontroller yang dibuat dengan dasar ATmega238p. Arduino UNO memiliki 14 pin digital ouput/input, Arduino UNO memiliki semua yang diperlukan untuk mensupport mikrokontroler, hanya perlu disambungkan ke komputer dengan kabel USB atau pada power dengan adapter AC ke DC atau baterai untuk memulainya[4]. Pengujian kontroler dilakukan dengan fungsi kontroler secara keseluruhan dengan hasil arduino UNO dapat berfungsi secara normal .dan dapat mengontrol komponen lain. 

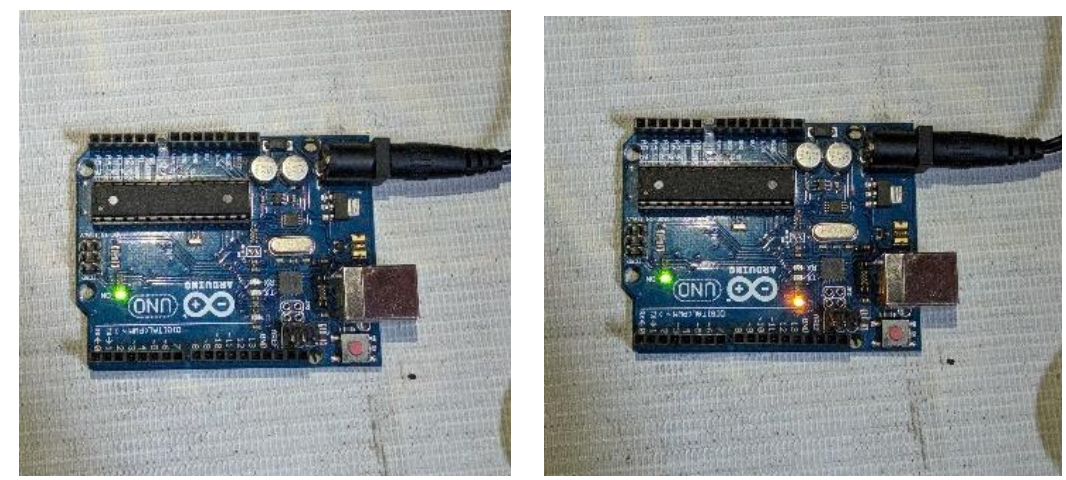

Gambar 4. Hasil program board arduino

Numeric keypad atau yang biasa disebut membrane keypad adalah peranti yang berguna untuk memasukkan angka[5].Pengujian keypad dilakukan dengan menggunakan kabel jumper dan arduino UNO, dengan hasil pada serial monitor dapat muncul sesuai dengan angka yang ditekan pada keypad.

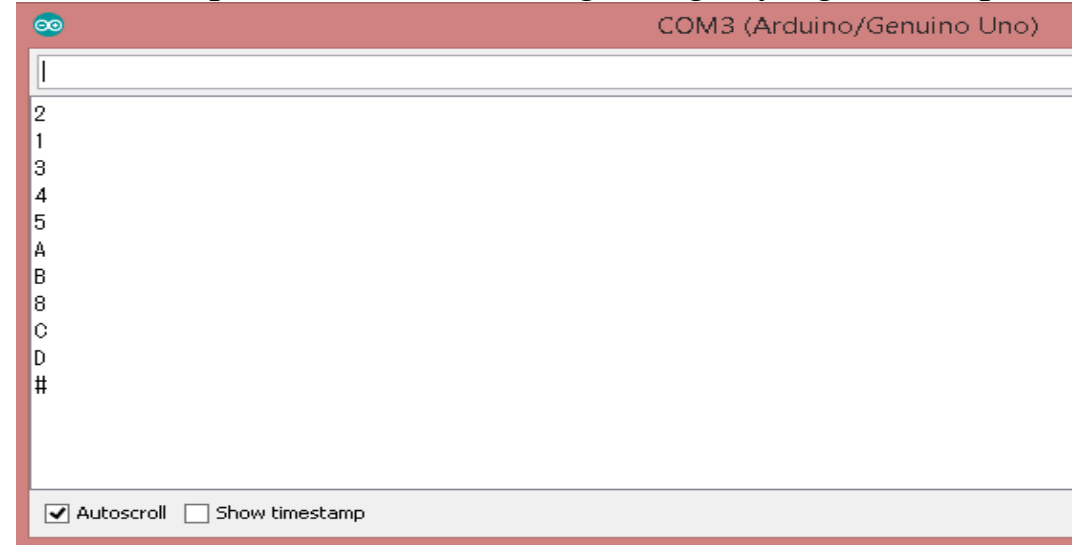

Gambar 5. Hasil penekanantombol keypad pada serial monitor

Pengujian LCD dilakukan dengan mencoba untuk menampilkan tulisan melalui coding, dengan hasil LCD dapat menampilkan tulisan sesuai dengan coding.

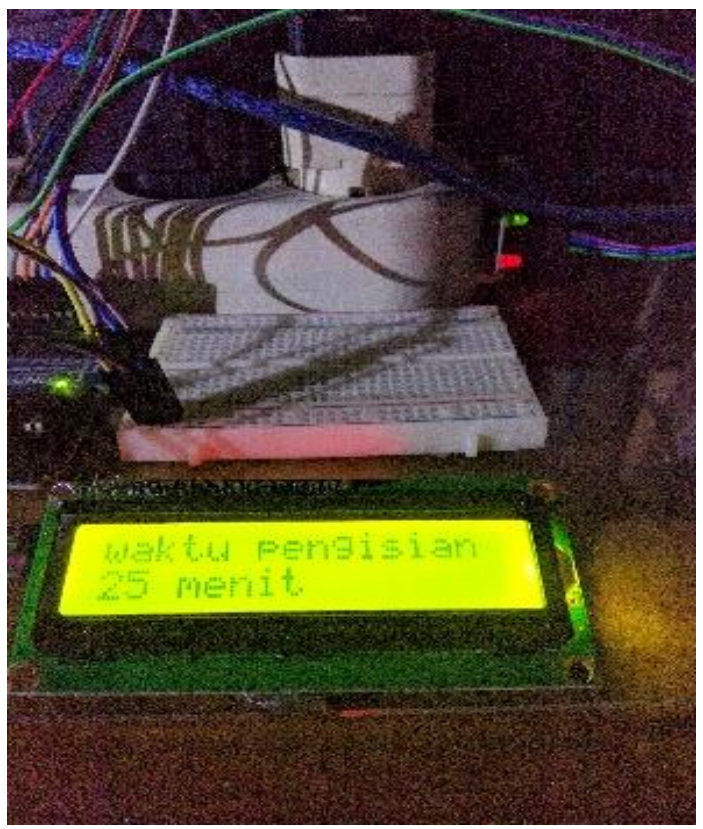

Gambar 6. Hasil pengujian LCD 
Pengujian relay dilakukan dengan menggunkan coding melalui arduino UNO dengan hasil relay dapat mati dan menyala kembali sesuai dengan program.
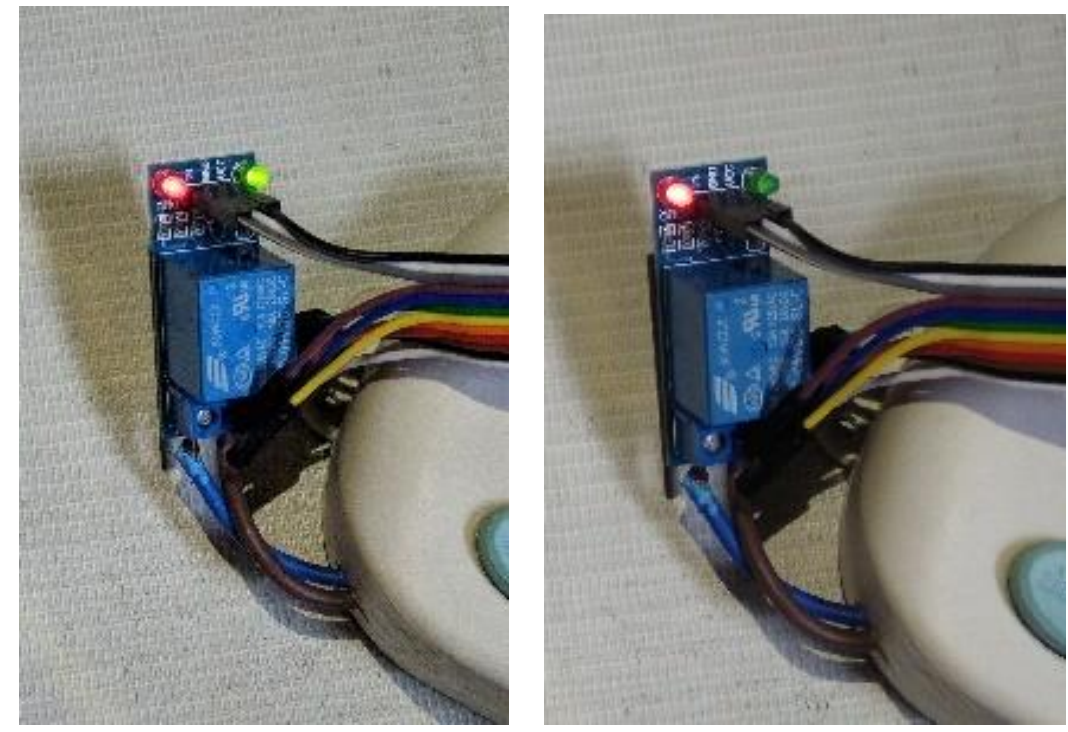

Gambar 7. Hasil pengujian relay

\section{Pengujian Komponen Utama Alat (keypad, relay, LCD , dan buzzer)}

Pengujian tiga komponen dilakukan secara bersamaan karena merupakan komponen-komponen inti dalam alat yang saling terhubung . pengujian pertama yaitu tombol bintang (*) pada keypad yang berfungsi sebagai reset komponen . ketika alat ditancapkan pada sumber tegangan maka setiap komponen akan menyala . tombol reset diperlukan untuk mengembalikan setiap komponen pada kondisi awal. LED indikator warna hijau pada relay yang menyala ketika awal alat dinyalakan akan mati karena tombol reset ditekan. pada gambar 4.19 adalah kondisi sebelum dan sesudah tombol reset ditekan.
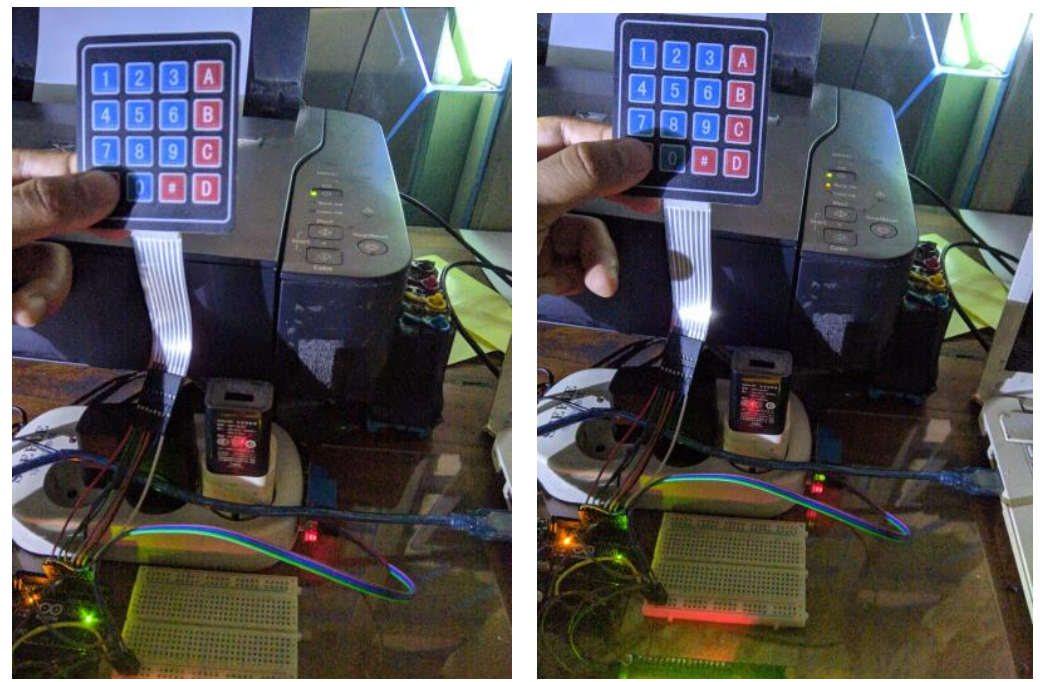

Gambar 8. pengujian tombol reset

Pengujian selanjutnya yaitu pengujian fungsi utama keypad untuk mengatur relay yang berkerja pada charger dan menampilkan waktu lamanya pengisian baterai sesuai dengan tombol yang dipencet. Pengujian 
dilakukan dengan menekan tombol angka satu yang mengontrol waktu pengisian dengan persentase sisa baterai 95\% hingga 99\% . apabila tombol satu ditekan maka LCD akan menampilkan waktu lamanya pengisian yaitu 25 menit dan akan menyalakan relay selama 25 menit. Kondisi alat setelah tombol angka satu ditekan adalah seperti pada gambar 9 .
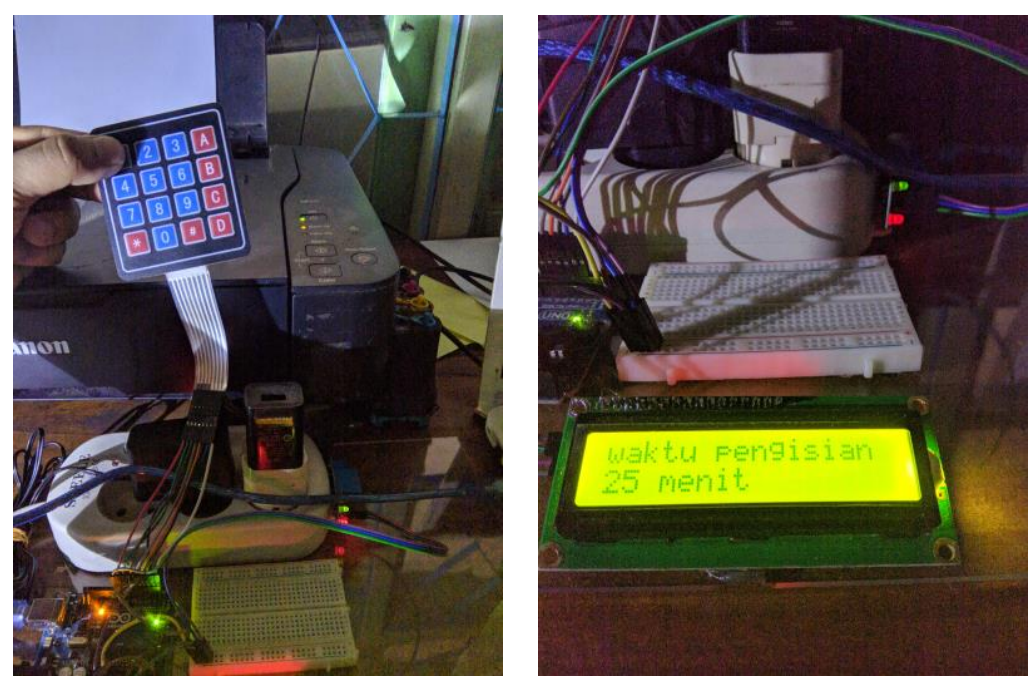

Gambar 9. kondisi alat setelah menyala

Setelah waktu pengisian yang ditentukan selesai maka relay akan mati dan buzzer akan menyala selama 10 detik. Indikator bahwa relay sudah mati ketika waktu pengisian sudah selesai adalah LED hijau yang menyala pada saat pengisian akan mati ketika sudah selesai dan layar LCD akan menampilkan tulisan " pengisian selesai” sebagai indikator kerja alat sudah selesai seperti pada gambar 10 .
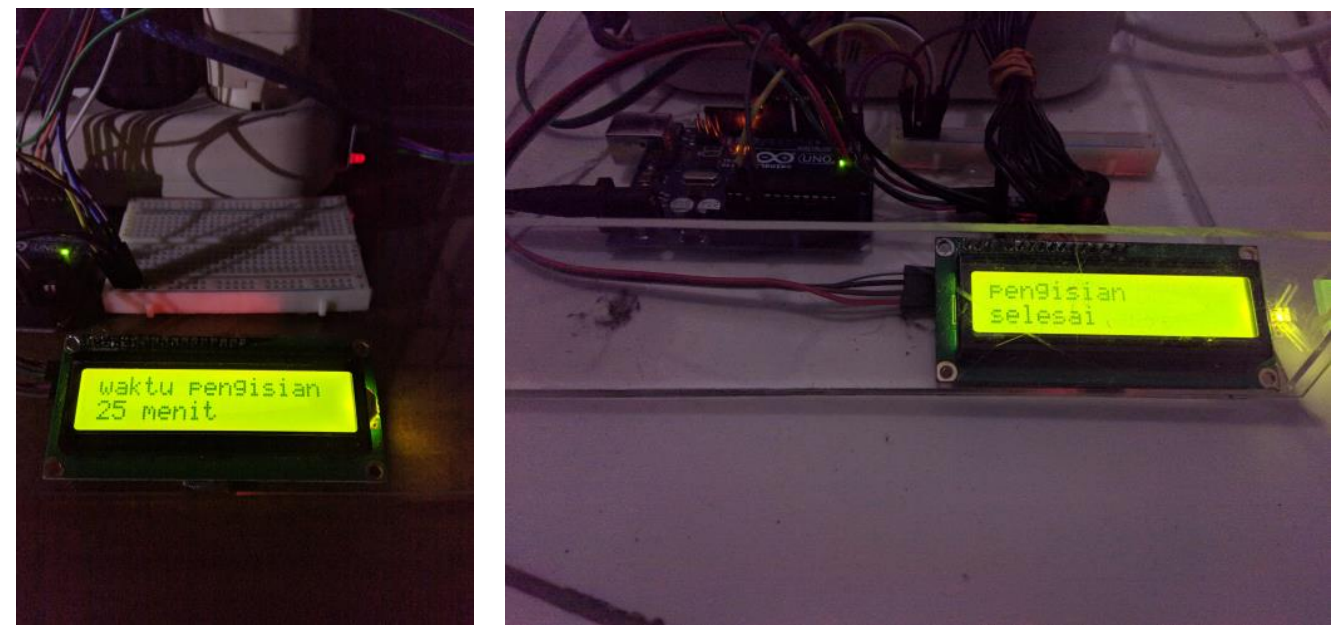

Gambar 10. kondisi ketika pengisian selesai

\section{Analisis Alat}

Analisis sistem merupakan analisa dari sistem alat yang telah berkerja secara keseluruhan. Berdasarkan hasil yang diperoleh dari pengujian alat semua sistem telah berkerja sesuai dengan fungsi alat. Akan tetapi alat tidak bisa melakukan pemindahan fungsi tombol secara langsung apabila sudah berjalan . Misalkan user menekan tombol angka satu dengan fungsi menyalakan charger selama 25 menit, maka alat tidak dapat 
menerima perintah lain sebelum selesai menyalakan charger selama 25 menit. Hal ini ini sesuai dengan fungsi mikrokontroler yang menjalankan semua fungsi sesuai dengan urutan coding arduino IDE.

Charger menentukan kecepatan pengisian baterai pada smartphone. Pada alat ini sudah dibekali dengan charger bawaan dari xiaomi agar bisa memaksimalkan kinerja dari alat. Charger apabila mengalami kerusakan baik pada adaptor maupun kabel USB akan menyebabkan pengisian baterai menjadi tidak normal.

Karakteristik dari charger $0.35 \mathrm{~A}$ xiaomi adalah daya yang masuk berbeda-beda sesuai dengan persentase baterai. Sesuai dengan hasil pengamatan langsung dengan hasil di bab 3. Pada awal pengisian dengan sisa persentase baterai dibawah 10\% daya yang masuk pada baterai mencapai maksimal 1900mAH, Sehingga semakin cepat untuk mengisi baterai. Kecepatan pengisian baterai akan menurun ketika sudah mencapai $50 \%$ dengan rata-rata 1750mAH. Ketika pengisian sudah mencapai 90\% menuju ke 100\% charger akan memasuki mode pengisian paling lambat dengan kecepatan pengisian antara 390mAH hingga 650mAH sehingga memerlukan waktu paling lama dibandingkan dengan persentase yang lain. Dari 3x pengujian alat memberikan hasil bahwa alat dapat mengontrol pengisian dengan menggunakan waktu yang telah ditentukan hingga mencapai persentase 98\% hingga 99\%. Kekurangan yang dimiliki oleh alat ini adalah yaitu ketika tombol keypad ditekan maka alat tidak dapat merespon jika ditekan tombol lain jika user salah menekan tombol. Dan juga ketika terjadi pemadamanan listrik yang menyebabkan alat berhenti bekerja, ketika sumber listrik kembali mengalir alat akan kembali ke kondisi awal berkerja yaitu relay dan buzzer menyala. Pada kondisi ini proses otomatisasi tidak akan berjalan karena user harus menekan tombol bintang (*) untuk melakukan reset pada relay dan buzzer. Hal ini dapat menyebabkan terjadinya overcharge apabila user meninggalkan alat dalam waktu yang lama . buzzer yang berbunyi terus menerus menjadi indikator apabila kondisi ini terjadi.

\section{KESIMPULAN}

Rancang bangun charger otomatis menggunakan Arduino UNO sebagai control terutama yang mengatur kineja dari semua komponen yang ada. Cara kerja alat ini adalah dengan menekan tombol pada keypad sesuai dengan persentase sisa baterai , relay akan menyala dengan waktu sesuai tombol keypad yang ditekan dan akan mati jika sudah selesai. Buzzer akan berbunyi sebagai tanda waktu pengisian telah selesai.

\section{SARAN}

Pembuatan rancang bangun charger otomatis pengontrol daya dan waktu berbasis arduino kedepannya diharapkan dapat dikembangkan agar bisa menjadi lebih baik kedepannya. Adapun saran yang dapat diberikan penulis adalah :

1. Pengembangan pada desain dan tata letak komponen pada alat sehingga dapat lebih sederhana dan menarik bagi user.

2. Pengembangan pada pengimputan persentase baterai yang dapat mencangkup persentase baterai dari 0\% hingga 99\%. Pengembangan dapat dilakukan dengan membuat tombol keypad custom agar dapat menyesuaikan jumlah tombol yang bisa digunakan dan dapat menambahkan keterangan fungsi pada masing-masing tombol.

3. Pengembangan pada alat agar dapat digunakan pada banyak jenis kapasitas baterai dapat dilakukan dengan menggunakan proses penghitungan waktu pengisian sesuai dengan kapasitas baterai yang diinputkan.

4. Pengembangan pada kelemahan alat. pada alat terdapat kelemahan yaitu jika ada pemutusan pada sumber tegangan (mati listrik) yang dapat menyebabkan alat berhenti bekerja . untuk penelitian kedepannya yang dapat mengatasi permasalahan tersebut dengan menggunakan sumber daya cadangan, misalkan dengan menggunakan baterai. 
5. Pengembangan pada kelemahan alat yang terjadi apabila user salah menekan tombol tanpa harus melakukan reset pada kontroler dapat dilakukan dengan menambahkan RTC sebagai pengganti penghitung waktu pada relay. RTC juga dapat digunakan sebagai timer hitungan waktu pengisian yang ditampilkan pada LCD.

\section{DAFTAR PUSTAKA}

[1] Indah rahmayani.2018.Indonesia Raksasa Teknologi Digital Asia. Diakses tanggal 22 desember 2018 .https://kominfo.go.id/content/detail/6095/indonesia-raksasa-teknologi-digital-asia/0/sorotan_media.

[2] Sugiyono. (2016). Metode Penelitian Kuantitatif, Kualitatif dan R\&D. Bandung: PT Alfabet

[3] Gunawan,Rusdianto.2017.'Perancangan Alat dan Sistem Smartcharger pada Smartphone Menggunakan Arduino".Fakultas Sains dan Teknologi. Universitas Alauddin.Makassar.

[4] https://store.arduino.cc/usa/arduino-uno-rev3

[5] Kadir,Abdul.2018.From Zero to A Pro : Arduino (Edisi Revisi). Yogyakarta.Penerbit ANDI 